\title{
The simulated clinical environment
}

Citation for published version (APA):

Tremblay, M-L., Lafleur, A., Leppink, J., \& Dolmans, D. H. J. M. (2017). The simulated clinical environment: Cognitive and emotional impact among undergraduates. Medical Teacher, 39(2), 181-187. https://doi.org/10.1080/0142159X.2016.1246710

Document status and date:

Published: 01/02/2017

DOI:

10.1080/0142159X.2016.1246710

Document Version:

Publisher's PDF, also known as Version of record

Document license:

Taverne

Please check the document version of this publication:

- A submitted manuscript is the version of the article upon submission and before peer-review. There can be important differences between the submitted version and the official published version of record.

People interested in the research are advised to contact the author for the final version of the publication, or visit the DOI to the publisher's website.

- The final author version and the galley proof are versions of the publication after peer review.

- The final published version features the final layout of the paper including the volume, issue and page numbers.

Link to publication

\footnotetext{
General rights rights.

- You may freely distribute the URL identifying the publication in the public portal. please follow below link for the End User Agreement:

www.umlib.nl/taverne-license

Take down policy

If you believe that this document breaches copyright please contact us at:

repository@maastrichtuniversity.nl

providing details and we will investigate your claim.
}

Copyright and moral rights for the publications made accessible in the public portal are retained by the authors and/or other copyright owners and it is a condition of accessing publications that users recognise and abide by the legal requirements associated with these

- Users may download and print one copy of any publication from the public portal for the purpose of private study or research.

- You may not further distribute the material or use it for any profit-making activity or commercial gain

If the publication is distributed under the terms of Article $25 \mathrm{fa}$ of the Dutch Copyright Act, indicated by the "Taverne" license above, 


\title{
The simulated clinical environment: Cognitive and emotional impact among undergraduates
}

\author{
Marie-Laurence Tremblay ${ }^{\mathrm{a}}$, Alexandre Lafleur ${ }^{\mathrm{b}}$, Jimmie Leppink ${ }^{\mathrm{c}}$ and Diana H. J. M. Dolmans ${ }^{\mathrm{c}}$ \\ ${ }^{\mathrm{a}}$ Faculty of Pharmacy, Laval University, Quebec City, Canada; ${ }^{\mathrm{b}}$ Department of Medicine, Faculty of Medicine, Laval University, Quebec \\ City, Canada; ${ }^{C}$ Faculty of Health, Medicine and Life Sciences, Maastricht University, Maastricht, The Netherlands
}

\begin{abstract}
Context: Simulated clinical immersion $(\mathrm{SCl})$ is used in undergraduate healthcare programs to expose the learner to real-life situations in authentic simulated clinical environments. For novices, the environment in which the simulation occurs can be distracting and stressful, hence potentially compromising learning.

Objectives: This study aims to determine whether SCl (with environment) imposes greater extraneous cognitive load and stress on undergraduate pharmacy students than simulated patients (SP) (without environment). It also aims to explore how features of the simulated environment influence students' perception of learning.

Methods: In this mixed-methods study, 143 undergraduate pharmacy students experienced both SCl and SP in a crossover design. After the simulations, participants rated their cognitive load and emotions. Thirty-five students met in focus groups to explore their perception of learning in simulation.

Results: Intrinsic and extraneous cognitive load and stress scores in $\mathrm{SCl}$ were significantly but modestly higher compared to SP. Qualitative findings reveal that the physical environment in $\mathrm{SCl}$ generated more stress and affected students' focus. In $\mathrm{SP}$, students concentrated on clinical reasoning. SCI stimulated a focus on data collection but impeded in-depth problem solving processes.

Conclusion: The physical environment in simulation influences what and how students learn. SCl was reported as more cognitively demanding than SP. Our findings emphasize the need for the development of adapted instructional design guide-
\end{abstract} lines in simulation for novices.

\section{Introduction}

Simulated clinical immersion $(\mathrm{SCl})$, a simulation modality which reproduces real-life situations in an authentic simulated workplace environment, has now become an educational imperative of clinical training in health professions education (Teteris et al. 2012). However, the assumption that learning in a highly authentic clinical environment leads to better transfer of learning is debatable (Norman et al. 2012), especially for junior students (Girzadas et al. 2007; Issenberg et al. 2011). For novices, who have limited clinical experience, unfamiliar learning environments can potentially be distracting rather than add meaning to a learning task (Van Merriënboer \& Sweller 2010). Current instructional design models hardly inform us on how to adapt the physical environment in simulation for undergraduate healthcare students in part because its cognitive and emotional impact remains misunderstood.

Simulation-based education provides meaningful learning opportunities for students to practice, to err, and to learn in a safe simulated environment (Ziv et al. 2003; Weller 2004; Cook et al. 2011; Cook et al. 2013). Different simulation modalities enable the alignment of task demands with the learning objectives (Chiniara et al. 2013; Hamstra et al. 2014). By design, SCl offers significant learning tasks closely connected and constantly interacting with the clinical environment, therefore reaching higher levels of the Miller's pyramid of clinical competency (Miller 1990). These learning activities are undoubtedly cognitively stimulating for novices. The type of cases presented in $\mathrm{SCl}$ may

\section{Practice points}

- Simulated clinical immersion and simulated patients are two simulation modalities commonly used for developing clinical reasoning skills.

- The interactions with the simulated physical environment are predominant in simulated clinical immersion, making it more cognitively challenging for novice learners with limited clinical experience.

- The simulated physical environment can be a source of stress and distractions, which can generate extraneous cognitive load for juniors.

- Interactions with the physical environment affect tranquility and influence the focus of learning.

- When designing simulated clinical immersion for novices, educators should adapt both the task and the learning environment to optimize learning.

comprise many new elements that still have to be integrated in students' cognitive schemas, which will contribute to intrinsic cognitive load, a type of cognitive load arising from processing the content to be learned (Leppink \& van den Heuvel 2015).

The physical environment in $\mathrm{SCl}$ is a double-edged knife because environmental factors might reinforce learning with the potential risk of causing stress and 
disturbance in less experienced participants (DeMaria \& Levine 2013). This risk may contribute substantially to extraneous cognitive load (Leppink \& van den Heuvel 2015), which is cognitive load that does not pertain to learning processes and consequently hinders rather than facilitates learning (Leppink et al. 2015). Since the combination of intrinsic and extraneous cognitive load has to respect the rather narrow limits of working memory capacity, education should be designed such that extraneous cognitive load is minimized and students are stimulated to optimally allocate their available resources to deal with the intrinsic cognitive load (Leppink et al. 2015). A recent mixed-methods study provided evidence for how it can be achieved in the context of the design of objective structured clinical examinations by changing task demands (Lafleur et al. 2015). Given the amount of human and material resources invested in the use of $\mathrm{SCl}$, it is pressing to explore how novices experience this simulation modality and how it affects their learning processes (Issenberg et al. 2011).

Recent evidence suggests that emotions experienced by learners during a simulation is directly linked with the cognitive load imposed on them (Fraser et al. 2012; Fraser et al. 2014). A growing amount of data demonstrates that excessive stress and anxiety produce a negative impact on learning, whereas positive emotions - particularly emotions associated with a pleasant state of mind - can either enhance or hinder learning (Darke 1988; Sorg \& Whitney 1992; Isen \& Reeve 2005; Fraser et al. 2014). Stress in simulation has been associated with a positive performance, up to a certain level after which detrimental effects on performance and learning can be observed (DeMaria \& Levine 2013; Fraser et al. 2014). Fraser et al. (2012) have demonstrated that increased invigoration and decreased tranquility during $\mathrm{SCl}$ training impose a greater cognitive load on medical students, which resulted in a poorer task performance. It is still unknown whether different simulation modalities have a different impact on emotions.

Among the different modalities, simulated patients (SP) are typically used to replicate encounters with real patients and are useful to learn history taking, physical examination, and clinical reasoning (Barrows 1993; Cleland et al. 2009). SPs are persons who have been trained to portray a patient with a specific condition in a realistic manner (Barrows 1993). As opposed to $\mathrm{SCl}$, the environment in which SP simulation takes place can be in either clinical or nonclinical settings, since it is not intended to interact directly with the learning tasks (Chiniara et al. 2013). Considering the additional environmental factors inherent to $\mathrm{SCl}$, we can hypothesize that this modality mobilizes more cognitive resources than SP (Maran \& Glavin 2003). More specifically, cognitive load theory predicts that the increase in maneuvers and other actions elevate intrinsic cognitive load, while an increased demand on problem-solving search contributes to a higher extraneous cognitive load (Leppink et al. 2015). The purpose of this study is to determine how $\mathrm{SCl}$ affects cognitive load and emotions compared to less resource-intensive SP simulation.

We designed this experiment to address the following research questions: What is the difference between $\mathrm{SCl}$ and $S P$ in terms of intrinsic and extraneous cognitive load, selfperceived learning, emotions, and overall appreciation of their experience for undergraduate pharmacy students? To understand what constituted intrinsic and extraneous cognitive load for our students and explore students' perception of learning during simulation, we studied qualitatively how do features of the simulated physical environment influence students' perception of learning? We hypothesize that, compared to SP, SCl increases intrinsic cognitive load (H1), does not increase self-perceived learning (H2) but rather elevates extraneous cognitive load (H3) and negative emotions (H4). Therefore, altogether, we have no reason to expect that students appreciate $\mathrm{SCl}$ more or less than SP (H5).

\section{Method}

\section{Setting}

This study was conducted from November 2014 to January 2015 at Laval University Faculty of Pharmacy (Quebec, Canada) in the Pharmacy Simulation Laboratory, which replicates a pharmacy workplace fully equipped with authentic material commonly found in community pharmacies. For instance, real medications, electronic pharmacy records, telephones, and electronic references and books are made available if required for a learning task.

\section{Participants}

Participants study in a 4-year competency-based pharmacy program (PharmD), entirely administered in French. Admission in the program is based on academic results and on psychometric test results. Participants were enrolled on a voluntary basis and had experienced four $\mathrm{SCl}$ and six SP activities prior to the experiment in the Pharmacy Simulation Laboratory. They were familiar with the different roles they played during the simulation. Sampling was made using cluster-randomization for the experiment. All students had prior knowledge on the targeted clinical contents of the cases.

\section{Intervention}

Participants experienced both $\mathrm{SP}$ and $\mathrm{SCl}$ in a crossover sequence (Figure 1). Based on quality features for designing simulation activities (Issenberg et al. 2005; Motola et al. 2013), both SP and SCI had the same course of events. Each simulation session started with a short briefing, followed by a case and a debriefing period. Three cases were experienced per simulation session separated by their related debriefings.

Participants played three different roles in rotation during these simulation sessions: the pharmacist, the patient (simulated patient), and the observer. When students played the patient, a role description was provided as well as a 10-min training prior to the simulation. One trained pharmacy simulation instructor conducted the simulations and the debriefing periods for both $\mathrm{SCl}$ and SP for all groups.

The main difference between $\mathrm{SP}$ and $\mathrm{SCl}$ in this study is the interactions with the physical environment. In SP, students had access to paper patients' file only, and telephones and medications were not available. Students therefore did not have to deliver the medication, to enter 


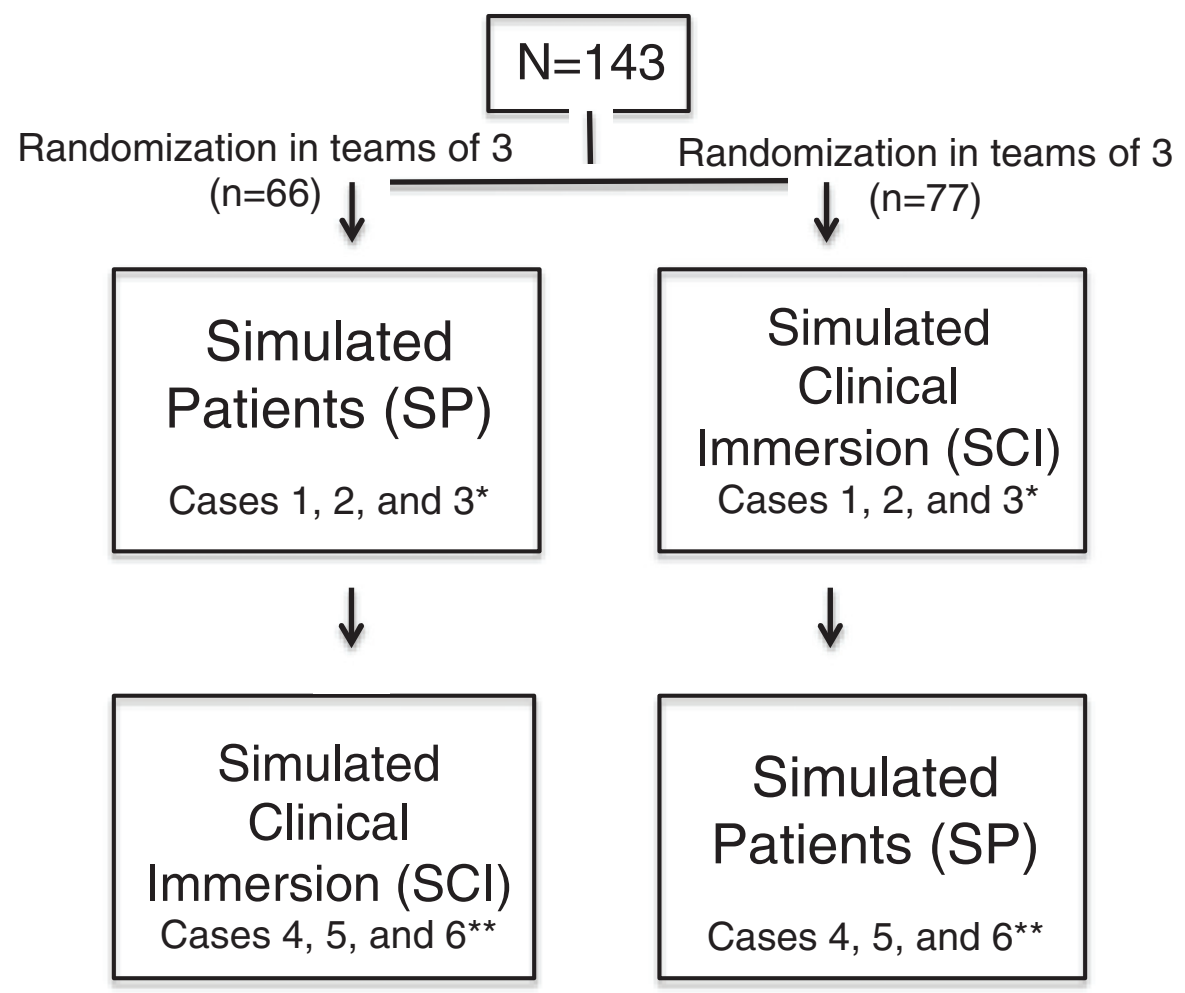

Figure 1. Randomization and experimental design.

information in patients' file, and to use the real telephone to communicate with a simulated third party (physician for example). Interactions with the physical environment were very limited in SP.

In $\mathrm{SCl}$, participants had to be able to select and deliver accordingly with the legislation the appropriate drugs based on the medication in stock in their pharmacy, use the electronic pharmacy records to retrieve and enter the necessary information, and use telephones to communicate with a simulated third party if required. Interactions with the physical environment were abundant in SCl.

\section{Quantitative data collection}

Immediately after each debriefing period, participants completed a three-section questionnaire, starting with a translated version (French) of the cognitive load questionnaire developed by Leppink et al. (2014) used to measure intrinsic and extraneous cognitive load, and self-perceived learning with 11-point (0-10) rating scales (see questionnaires in Appendix 1).

The second section of the questionnaire involved rating emotions associated with the simulation using an eightitem scale containing bipolar oppositional descriptors of emotion suggested by Feldman Barrett and Russell (1998). The oppositional descriptors were tense/calm, nervous/ relaxed, stressed/serene, upset/contented, sad/happy, depressed/elated, lethargic/excited, and bored/alert. Participants were asked to rate each bipolar emotion descriptor from -2 to +2 , where positive values represent a more pleasant state of mind and negative values are associated with an undesirable mood. This instrument has been tested on medical students during simulation sessions (Fraser et al. 2012, 2014). In these studies, a factor analysis revealed two principal components. The descriptors tense/ calm, nervous/relaxed, and stressed/serene were characterized as tranquility, whereas the remaining five represented invigoration (upset/contented, sad/happy, depressed/elated, lethargic/excited, and bored/alert).

In total, each participant filled out six times the questionnaires (cognitive load and emotions) - three times per session - each time immediately after the debriefing period.

Finally, once per session, participants had to rate their appreciation of both $\mathrm{SCl}$ and SP using 0-10 rating scales. We considered that scores of 8 and above would be excellent, 7 would be satisfactory, and 6 or below would be insufficient, meaning that simulation modality would not be of sufficient quality and would require improvement.

\section{Quantitative analysis}

Quantitative analysis was performed with IBM SPSS version 23.0 (IBM Corp., Armonk, NY). To test our five hypotheses H1-H5 while accounting for the characteristics of the crossover design and the few missing responses in the outcome variables of interest, we performed mixed-effects (multilevel) models (Leppink 2015; Leppink \& van Merriënboer 2015). We specified simulation type (SCl vs. SP) and role (pharmacist, patient, observer) as fixed effects and studentlevel random intercepts as random effects.

Internal consistency for each scale was sufficient for the cognitive load and the emotion-rating questionnaires, and quality-assurance items. All Cronbach's alpha coefficients were above 0.7, except for extraneous cognitive load in SP for the three roles $(\alpha=0.577,0.662$ and 0.697$)$.

\section{Qualitative data collection and analyses}

As part of an explanatory sequential design, 2 months after the simulation sessions, participants were convened to participate in focus groups, which were conducted by one 
author (M.L.T.). The purpose of collecting qualitative data was to understand what contributed to intrinsic and extraneous cognitive load for our students and explore their perception of learning during simulation. Thirty-five volunteers who had experienced the simulations were divided into six different groups using maximal variation sampling based on the correlation between differences in extraneous cognitive load and tranquility. Open questions were asked on students' perception of learning during SP and $\mathrm{SCl}$ and elements that enhance or hinder learning in simulation (see focus group questions in Appendix 2).

Focus groups were audio-recorded and transcribed integrally. The interviewer listened to the interviews and coded the content of the discussions. A second author (A.L.) listened to $50 \%$ of the interviews and validated the coding (topics, themes). In case of disagreement, discussions between the authors occurred until an agreement was reached, although no major issues arose during the analysis.

\section{Ethical considerations}

This study received approval from the Research Ethics Committee of Laval University (\# 2014-217). Written informed consents were obtained prior to randomization. Participants were asked to reiterate their consent to participate to the focus groups. They were made aware that the research material would remain confidential and that performance during the simulations would not be used for assessment purposes. Investigators were not directly involved with students' training at the moment of conducting the research.

\section{Results}

\section{Quantitative results}

One hundred and seventy-four second-year undergraduate pharmacy students were invited to participate to this study. One hundred forty-three students (average age of 21.75 with a standard deviation of $2.46 ; 71 \%$ female) responded positively and were representative of the studied population (response rate of $82.2 \%$ ).

Table 1 presents means and standard deviations for each of the outcome variables for each combination of simulation type and role. Table 2 presents the outcomes of mixed-effects analysis for each of the response variables.

In line with $\mathbf{H 1}$ (intrinsic cognitive load) and H3 (extraneous cognitive load), the presented findings indicate that intrinsic and extraneous cognitive load were on average significantly higher in $\mathrm{SCl}$ than in $\mathrm{SP}$, and in line with $\mathbf{H 4}$, tranquility was on average somewhat lower in $\mathrm{SCl}$ as well. Further, we did not find convincing evidence against H5 that $\mathrm{SCl}$ and SP are appreciated about the same. However, not in line with $\mathbf{H 2}$, the findings with regard to self-perceived learning do appear to indicate a slight preference toward $\mathrm{SCl}$.

\section{Qualitative results}

The focus groups added enlightenment to the quantitative analysis by identifying, which elements of the simulation
Table 1. Means $(M)$ and standard deviations (SD) [and sample size $n$ ] for each of the outcome variables for each combination of simulation type and role.

\begin{tabular}{|c|c|c|}
\hline Condition & SP & $\mathrm{SCl}$ \\
\hline \multicolumn{3}{|l|}{ Intrinsic cognitive load $(0-10)$} \\
\hline Pharmacist & $4.30(2.06)[n=143]$ & $4.72(2.03)[n=143]$ \\
\hline Observer & $4.08(1.71)[n=142]$ & $4.28(1.85)[n=140]$ \\
\hline Patient & $4.04(1.77)[n=142]$ & $4.34(1.79)[n=143]$ \\
\hline \multicolumn{3}{|l|}{ Extraneous cognitive load $(0-10)$} \\
\hline Pharmacist & $1.60(1.59)[n=141]$ & $2.95(2.14)[n=143]$ \\
\hline Observer & $1.12(1.26)[n=141]$ & $1.86(1.71)[n=142]$ \\
\hline Patient & $1.14(1.16)[n=140]$ & $1.69(1.74)[n=138]$ \\
\hline \multicolumn{3}{|l|}{ Self-perceived learning (0-10) } \\
\hline Pharmacist & $7.02(1.76)[n=143]$ & $7.43(1.40)[n=143]$ \\
\hline Observer & $6.83(1.67)[n=140]$ & $7.29(1.50)[n=142]$ \\
\hline Patient & $6.84(1.65)[n=142]$ & $7.02(1.55)[n=140]$ \\
\hline \multicolumn{3}{|l|}{ Tranquility $^{\mathrm{a}}(-2$ to +2$)$} \\
\hline Pharmacist & $0.66(1.09)[n=143]$ & $0.35(1.15)[n=142]$ \\
\hline Observer & $1.41(0.85)[n=142]$ & $1.32(0.87)[n=143]$ \\
\hline Patient & $1.36(0.81)[n=143]$ & $1.30(0.88)[n=142]$ \\
\hline \multicolumn{3}{|l|}{ Invigoration ${ }^{\mathrm{b}}(-2$ to +2$)$} \\
\hline Pharmacist & $0.97(0.76)[n=143]$ & $0.96(0.78)[n=143]$ \\
\hline Observer & $1.13(0.75)[n=142]$ & $1.16(0.80)[n=140]$ \\
\hline Patient & $1.17(0.76)[n=143]$ & $1.14(0.75)[n=142]$ \\
\hline \multicolumn{3}{|l|}{ Students' appreciation (0-10) } \\
\hline No distinction between roles & $8.77(1.14)[n=142]$ & $8.83(1.06)[n=142]$ \\
\hline
\end{tabular}

Table 2. Outcomes of mixed-effects analysis for each of the response variables.

\begin{tabular}{|c|c|c|c|}
\hline Effect & $\mathrm{df1}, \mathrm{df} 2$ & $F$ value & $p$ Value \\
\hline $\begin{array}{l}\text { Intrinsic cognitive load } \\
\text { Role }^{\mathrm{a}} \\
\text { Simulation }^{\mathrm{a}} \\
\text { Simulation by role }\end{array}$ & $\begin{array}{l}2,565.851 \\
1,142.817 \\
2,566.150\end{array}$ & $\begin{array}{l}4.067 \\
5.960 \\
0.361\end{array}$ & $\begin{array}{l}0.018 \\
0.016 \\
0.697\end{array}$ \\
\hline $\begin{array}{l}\text { Extraneous cognitive lo } \\
\text { Role }^{\mathrm{a}} \\
\text { Simulation }^{\mathrm{a}} \\
\text { Simulation by role }\end{array}$ & $\begin{array}{l}2,554.896 \\
1,140.349 \\
2,555.128\end{array}$ & $\begin{array}{r}44.260 \\
48.616 \\
8.519\end{array}$ & $\begin{array}{l}<0.001 \\
<0.001 \\
<0.001\end{array}$ \\
\hline $\begin{array}{l}\text { Self-perceived learning } \\
\text { Role }^{\mathrm{a}} \\
\text { Simulation }^{\mathrm{a}} \\
\text { Simulation by role }^{\mathrm{b}}\end{array}$ & $\begin{array}{l}2,560.984 \\
1,141.493 \\
2,560.775\end{array}$ & $\begin{array}{r}4.769 \\
11.233 \\
0.850\end{array}$ & $\begin{array}{l}0.009 \\
0.001 \\
0.428\end{array}$ \\
\hline $\begin{array}{l}\text { Tranquility } \\
\text { Role }^{\mathrm{a}} \\
\text { Simulation }^{\mathrm{a}} \\
\text { Simulation by role }^{\mathrm{b}}\end{array}$ & $\begin{array}{l}2,565.621 \\
1,141.761 \\
2,565.624\end{array}$ & $\begin{array}{r}122.761 \\
6.115 \\
2.480\end{array}$ & $\begin{array}{r}<0.001 \\
0.015 \\
0.085\end{array}$ \\
\hline $\begin{array}{l}\text { Invigoration } \\
\text { Role }^{\mathrm{a}} \\
\text { Simulation }^{\mathrm{a}} \\
\text { Simulation by role }^{\mathrm{b}}\end{array}$ & $\begin{array}{l}2,563.933 \\
1,142.111 \\
2,563.928\end{array}$ & $\begin{array}{r}14.017 \\
0.012 \\
0.293\end{array}$ & $\begin{array}{r}<0.001 \\
0.913 \\
0.746\end{array}$ \\
\hline $\begin{array}{l}\text { Students' appreciation } \\
\text { Simulation }\end{array}$ & 1, 708.986 & 2.780 & 0.096 \\
\hline
\end{tabular}

${ }^{a}$ Main effect.

${ }^{b}$ Interaction effect.

(environment and learning task) mobilized their mental efforts and how the simulated physical environment influences students' perception of learning. Data saturation was reached after three of the six focus groups.

\section{Students learn clinical reasoning in SP}

Although all cases were designed to develop clinical reasoning, students confirm their deeper engagement in clinical reasoning during SP because they felt that they had more time to focus on the clinical cases rather than on technical aspects of the environment. They also felt that 
they could interact more with their simulated patient during SP.

In SP, we develop more our clinical judgement. I felt we had more time to think and practice our counselling. (P431)

\section{Students practice data collection in SCI}

Students admitted not to engage as deeply in problem solving in $\mathrm{SCl}$, because they essentially focus on data collection. They invested considerably more mental effort in locating and collecting information from the patient's authentic computer file, which distracted them from actually solving the problem once recognized. In the end, $\mathrm{SCl}$ helps novices develop autonomy with technical skills rather than engaging in deep problem solving.

In $\mathrm{SCl}$, we develop strategies to collect information and analyse the patient's file. (P213)

\section{The physical environment of SCI was considered stressful and probably hinders learning}

Most students reported the physical environment, but not all aspects of it, as stressful. They mention that the environment mobilizes mental effort in SCl. For example, accessing and consulting the patient's electronic pharmacy records was more demanding for most students compared to paper files. Consequently, students have less time for experiencing the rest of the case, if they even finish it, which adds to performance anxiety. Even though they are familiar with software and common pharmaceutical websites, all students do not refer to them effortlessly. Having access to telephones and medications was less stressful and did not seem to influence students' perception of learning.

\footnotetext{
I learned more in $\mathrm{SP}$, because in $\mathrm{SCl}$, there were too many things to consider at the same time, it was just too much. (P601)

I am more stressed in SCl. I try to think, but when I am stressed, I just don't compute! (P151)
}

\section{Performance anxiety is inherent, even in the absence of formal assessment}

Students reported that being observed by peers and teachers while playing the pharmacist contributes to the stress of performance. Other roles in the simulation, such as the patient and the observer, are not associated with performance anxiety. Performance anxiety was present in both SP and $\mathrm{SCl}$ even though the simulations were presented as learning activities and did not comprise any formal assessment of performance.

The fact that we are being observed or filmed is stressing [in both SP and $\mathrm{SCl}$ ]. I don't perform well when I am feeling evaluated. But I don't know if the fact that I did not perform well hinders my learning, maybe... (P111)

\section{Discussion}

This study helps to understand how the simulated physical environment influences students' perception of learning in simulation. Students reported on average higher intrinsic and extraneous cognitive load scores and slightly more negative emotions in $\mathrm{SCl}$ compared to $\mathrm{SP}$, as well as a somewhat higher self-perceived learning score. These results confirm our hypothesis that $\mathrm{SCl}$ is more cognitively challenging for novices, because it requires them to be able to deal with more information at the same time. In terms of task complexity, which is mainly determined by the degree to which elements within the task interact and by the number of interactions with the environment (Van Merriënboer \& Sweller 2010; Choi et al. 2014), SCI is unsurprisingly perceived as slightly more complex since students had to perform additional technical steps (e.g. preparing the medication, entering information in the patient's file, use the real telephones to communicate with the physician if needed) that resulted from interactions between the task and the environment. Nevertheless, the principal learning objectives both in SP and $\mathrm{SCl}$ aimed at developing clinical reasoning and problem-solving skills in various clinical situations, although in $\mathrm{SCl}$, students incidentally developed technical and administrative sub-skills associated with the primary tasks. Our qualitative findings indicate that the interactions with the physical environment can influence the very nature of what students learn (data collection only in $\mathrm{SCl}$ and problem-solving in SP), even though we did not intend it. To our knowledge, this is the first study that highlights the impact of the physical environment in simulation on students' perception of learning. Immersing junior pharmacy students in a highly authentic clinical environment can potentially lead to a shift of focus and prevent them from learning what they should have learned. Others studies are needed to confirm whether this effect is also observed in other healthcare disciplines. Both SP and $\mathrm{SCl}$ are powerful educational tools for skills training, but extraneous cognitive load arising from the physical environment should not be underestimated when selecting a simulation modality to match with the learning objectives (Choi et al. 2014; Hamstra et al. 2014).

Our quantitative and qualitative results show that students experience stress and performance anxiety in $\mathrm{SCl}$, but also in SP. In our study, simulations were designed to minimize sources of stress by avoiding performance assessment and unfamiliar environments. Although students described being observed by peers and videotaped as stressful, these aspects are very common features of simulation activities used to facilitate feedback and debriefing (Fanning \& Gaba 2007) and to encourage deliberate practice (Issenberg et al. 2005). By nature, simulation engenders stress and extraneous cognitive load, even with our best effort to put our students in a comfortable and safe learning environment (LeBlanc et al. 2014). Emotions experienced during simulations are proven to affect a variety of cognitive processes in short or long-term, such as decision-making, attention, and memory (LeBlanc 2009; LeBlanc et al. 2014). For example, recent evidence suggests that exposing medical students to deteriorating cases in simulation engenders more stress and leads to negative short-term learning outcomes (Fraser et al. 2014). Our study focused only on the immediate effect of simulation, which showed that small environmental changes affect tranquility and influence the focus of learning (problem solving vs. data collection). We are, however, lacking of evidence with regards to long-term retention of information learned in stressful simulations in health professions education.

In our study, differences between $\mathrm{SCl}$ and $\mathrm{SP}$ in average intrinsic and extraneous cognitive load were on the proximal end of the scale. Although this may indicate that - for learners comparable to the participants in the current study 
- SP and $\mathrm{SCl}$ are not that different in terms of cognitive load, it might also reflect to some extent that cognitive load research thus far has not really considered the effect of the physical environment on the learner's perception of the learning task (Choi et al. 2014). A recent systematic review on the validity of cognitive load measures in simulation-based education demonstrated that, although cognitive load theory is an interesting framework for instructional design in healthcare simulation training, current tools to measure cognitive load seem to engender inconsistent correlations between cognitive load and learning outcomes in the context of simulation (Naismith \& Cavalcanti 2015). These findings can partially explain why our quantitative findings indicate a rather modest difference between the modalities and why our qualitative findings are more polarized. We believe that current cognitive load questionnaires do not fully grasp the sources of extraneous cognitive load in simulation, revealing the need for the development of adapted tools to adequately measure the components of cognitive load in simulation (Haji et al. 2015; Naismith et al. 2015).

\section{Conclusion}

Simulation-based education offers meaningful learning opportunities for undergraduate healthcare students without compromising patients' safety, but emotions experienced during the simulation and the environment in which it takes place will impact what and how students learn. Regulating the simulated physical environment changes how students attend to learning objectives, emphasizing educators' role in designing simulation tasks and environments adapted to the learners' needs (Sandars et al. 2015).

\section{Acknowledgements}

We are grateful for the collaboration of Geneviève Lesage who acted as a simulation instructor for this study. We are also thankful for the support of the program director and direction of the Faculty of Pharmacy at Laval University for authorizing this research. We also want to thank the technical staffs at Apprentiss Simulation Center Pharmacy for supervising the technical aspects of this study. Finally, we are grateful for the support of Dr Andreas Gegenfurtner and Prof. Jan-Joost Rethans who provided feedback on the design and manuscript.

\section{Disclosure statement}

The authors report no conflicts of interest. The authors alone are responsible for the content and writing this article.

\section{Glossary}

Simulated Clinical Immersion: Simulated clinical immersion is a simulation modality reproducing real-life situations in an authentic simulated workplace environment. It may comprise simulated patients and/or simulators if required within the simulation scenario. This simulation modality is typically used to develop clinical reasoning skills and team training.

Chiniara G, Cole G, Brisbin K, Huffman D, Cragg B, Lamacchia M, Norman D. 2013. Simulation in healthcare: a taxonomy and a conceptual framework for instructional design and media selection. Med Teach. 35:e1380-e1395.

\section{Notes on contributors}

Marie-Laurence Tremblay, B.PHARM, M.Sc., M.Sc., BCPS, is a pharmacist and a simulation educator at Centre Apprentiss, Université Laval, Canada.

Alexandre Lafleur, M.D., M.Sc., FRCPC, is a general medical internist at $\mathrm{CHU}$ de Québec and an educator at Université Laval, Canada.

Jimmie Leppink, $\mathrm{PhD}$, is a postdoctoral researcher at the School of Health Professions Education (SHE), Maastricht University, The Netherlands. His research focuses on adaptive approaches to learning and assessment, cognitive load theory and measurement, and multilevel analysis of educational data.

Diana Dolmans, $\mathrm{PhD}$, is Professor at the School of Health Professions Education (SHE) Maastricht University in the Netherlands. Her special interest relates to teaching and learning in innovative learning environments.

\section{References}

Barrows HS. 1993. An overview of the uses of standardized patients for teaching and evaluating clinical skills. AAMC. Acad Med. 68:443-451.

Chiniara G, Cole G, Brisbin K, Huffman D, Cragg B, Lamacchia M, Norman D. 2013. Simulation in healthcare: a taxonomy and a conceptual framework for instructional design and media selection. Med Teach. 35:e1380-e1395.

Choi HH, van Merriënboer JJ, Paas F. 2014. Effects of the physical environment on cognitive load and learning: towards a new model of cognitive load. Educ Psychol Rev. 26:225-244.

Cleland JA, Abe K, Rethans JJ. 2009. The use of simulated patients in medical education: AMEE Guide No 42. Med Teach. 31:477-486.

Cook DA, Hamstra SJ, Brydges R, Zendejas B, Szostek JH, Wang AT, Erwin PJ, Hatala R. 2013. Comparative effectiveness of instructional design features in simulation-based education: systematic review and meta-analysis. Med Teach. 35:e867-e898.

Cook DA, Hatala R, Brydges R, Zendejas B, Szostek JH, Wang AT, Erwin PJ, Hamstra SJ. 2011. Technology-enhanced simulation for health professions education: a systematic review and meta-analysis. JAMA. 306:978-988.

Darke S. 1988. Effects of anxiety on inferential reasoning task performance. J Pers Soc Psychol. 55:499-505.

DeMaria S, Levine A. 2013. The use of stress to enrich the simulated environment. In: Levine A, DeMaria S, Schwartz A, Sim A, editors. The comprehensive textbook of healthcare simulation. New York: Springer; p. 65-72. doi: 10.1007/978-1-4614-5993-4_5.

Fanning RM, Gaba DM. 2007. The role of debriefing in simulationbased learning. Simul Healthc. 2:115-125.

Feldman Barrett L, Russell JA. 1998. Independence and bipolarity in the structure of current affect. J Pers Soc Psychol. 74:967-984.

Fraser K, Huffman J, Ma I, Sobczak M, Mcllwrick J, Wright B, McLaughlin K. 2014. The emotional and cognitive impact of unexpected simulated patient death: a randomized controlled trial. Chest J. 145:958-963.

Fraser K, Ma I, Teteris E, Baxter H, Wright B, McLaughlin K. 2012. Emotion, cognitive load and learning outcomes during simulation training. Med Educ. 46:1055-1062.

Girzadas DV Jr, Clay L, Caris J, Rzechula K, Harwood R. 2007. High fidelity simulation can discriminate between novice and experienced residents when assessing competency in patient care. Med Teach. 29:472-476.

Haji FA, Rojas D, Childs R, Ribaupierre S, Dubrowski A. 2015. Measuring cognitive load: performance, mental effort and simulation task complexity. Med Educ. 49:815-827.

Hamstra SJ, Brydges R, Hatala R, Zendejas B, Cook DA. 2014. Reconsidering fidelity in simulation-based training. Acad Med. 89:387-392.

Isen AM, Reeve J. 2005. The influence of positive affect on intrinsic and extrinsic motivation: Facilitating enjoyment of play, responsible work behavior, and self-control. Motiv Emot. 29:295-323.

Issenberg S, McGaghie W, Petrusa E, Lee Gordon D, Scalese R. 2005 Features and uses of high-fidelity medical simulations that lead to effective learning: a BEME systematic review. Med Teach. 27:10-28. 
Issenberg SB, Ringsted C, Østergaard D, Dieckmann P. 2011. Setting a research agenda for simulation-based healthcare education: a synthesis of the outcome from an Utstein style meeting. Simul Healthc. 6:155-167.

Lafleur A, Côté L, Leppink J. 2015. Influences of OSCE design on students' diagnostic reasoning. Med Educ. 49:203-214.

LeBlanc VR. 2009. The effects of acute stress on performance: implications for health professions education. Acad Med. 84:S25-S33.

LeBlanc VR, McConnell MM, Monteiro SD. 2014. Predictable chaos: a review of the effects of emotions on attention, memory and decision making. Adv Health Sci Educ Theory Pract. 20:265-282.

Leppink J. 2015. Data analysis in medical education research: a multilevel perspective. Perspect Med Educ. 4:14-24.

Leppink J, Paas F, Van Gog T, Van der Vleuten CP, Van Merrienboer JJ. 2014. Effects of pairs of problems and examples on task performance and different types of cognitive load. Learn Instruct. 30:32-42.

Leppink J, van den Heuvel A. 2015. The evolution of cognitive load theory and its application to medical education. Perspect Med Educ. 4:119-127.

Leppink J, van Gog T, Paas F, Sweller J. 2015. Cognitive load theory: researching and planning teaching to maximize learning. In Cleland J, Durning SJ, editors. Researching medical education. New York, NY: John Wiley \& Sons, Ltd. p. 207-218.

Leppink J, van Merriënboer JJ. 2015. The beast of aggregating cognitive load measures in technology-based learning. Learning. 18:230-245.

Maran N, Glavin R. 2003. Low-to high-fidelity simulation - a continuum of medical education? Med Educ. 37:22-28.

Miller GE. 1990. The assessment of clinical skills/competence/performance. Acad Med. 65:S63-S67.

Motola I, Devine LA, Chung HS, Sullivan JE, Issenberg SB. 2013. Simulation in healthcare education: a best evidence practical guide. AMEE Guide No. 82. Med Teach. 35:e1511-e1530.

Naismith LM, Cavalcanti RB. 2015. Validity of cognitive load measures in simulation-based training: a systematic review. Acad Med. 90:S24-S35.

Naismith LM, Cheung JJ, Ringsted C, Cavalcanti RB. 2015. Limitations of subjective cognitive load measures in simulation-based procedural training. Med Educ. 49:805-814.

Norman G, Dore K, Grierson L. 2012. The minimal relationship between simulation fidelity and transfer of learning. Med Educ. 46:636-647.

Sandars J, Patel RS, Goh PS, Kokatailo PK, Lafferty N. 2015. The importance of educational theories for facilitating learning when using technology in medical education. Med Teach. 37:1039-1042.

Sorg BA, Whitney P. 1992. The effect of trait anxiety and situational stress on working memory capacity. J Res Pers. 26:235-241.

Teteris E, Fraser K, Wright B, McLaughlin K. 2012. Does training learners on simulators benefit real patients? Adv Health Sci Educ Theory Pract. 17:137-144.

van Merriënboer JJ, Sweller J. 2010. Cognitive load theory in health professional education: design principles and strategies. Med Educ. 44:85-93.

Weller J. 2004. Simulation in undergraduate medical education: bridging the gap between theory and practice. Med Educ. 38:32-38.

Ziv A, Wolpe P, Small S, Glick S. 2003. Simulation-based medical education: an ethical imperative. Acad Med. 78:783-788.

\section{Appendix 1}

\section{Questionnaires}

Part I: Cognitive load questionnaire by Leppink et al. (2014) All of the following questions refer to the case-debriefing that just finished. Please take your time to read each of the questions carefully and respond to each of them on a scale from 0 to 10 , in which " 0 " means not at all and " 10 " means completely the case.

1. The content of this activity was very complex.

2. The problems covered in this activity were very complex.

3. In this activity, very complex terms were mentioned.

4. I invested a very high mental effort in the complexity of this activity.

5. The explanations and instructions in this activity were very unclear.

6. The explanations and instructions in this activity were full of unclear language.

7. The explanations and instructions in this activity were, in terms of learning, very ineffective.
8. I invested a very high mental effort in unclear and ineffective explanations and instructions in this activity.

9. This activity really enhanced my understanding of the content that was covered.

10. This activity really enhanced my understanding of the problems that were covered.

11. This activity really enhanced my knowledge of the terms that were mentioned.

12. This activity really enhanced my knowledge and understanding of how to deal with the problems covered.

13. I invested a very high mental effort during this activity in enhancing my knowledge and understanding.

Questions 1-4 are meant to evaluate intrinsic cognitive load, and questions 5-8 estimate extraneous cognitive load. Questions 9-13 reflect selfperceived learning (former "germane cognitive load").

\section{Part II: Emotion-rating questionnaire Bipolar oppos- itional descriptors of emotion as suggested by Feldman} et al. (1998)

The following items confront two opposite emotions. While referring to the case-debriefing period that just finished, please take your time to read each items and rate from -2 to 2 the emotions you felt, where a negative value is associated with an undesirable experience and a positive value is associated with a more pleasant experience.
1. Tense $(-) /$ calm $(+)$
2. Nervous $(-)$ /relaxed $(+)$
3. Stressed $(-)$ /serene $(+)$
4. Upset $(-) /$ contented $(+)$
5. Sad $(-)$ /happy $(+)$
6. Depressed (-)/elated $(+)$
7. Lethargic $(-)$ /excited $(+)$
8. Bored (-)/Alert $(+)$

Items 1-3 are intended to evaluate Tranquility, whereas items 4-8 measure Invigoration, as suggested by Fraser et al. (2012).

\section{Part III: Quality assurance questions Inspired by the} quality features from Issenberg et al. (2005)

All of the following questions refer to the case-debriefing that just finished. Please take your time to read each of the questions carefully and respond to them on a scale from 0 to 10 , in which " 0 " means not at all and " 10 " means completely the case.

1. The case reflects a real-life situation.

2. The case was in line with the prior content in our program.

3. The debriefing period helped me understand or reinforce my understanding of the problem solving reasoning steps.

4. I had the opportunity, if needed, to ask questions and/or get answers to my questions by peers or by the instructor.

5. I learned a lot during this activity (case and debriefing).

6. I feel more confident to deal with a similar situation in real life in the future.

\section{Appendix 2}

\section{Focus group questions}

The following questions were asked during the focus group interviews.

- What is your general impression of the two simulation sessions you have experienced? Did you notice something different? Why?

- Are you under the impression that you have learned more in one modality? Why?

- Which aspects of the simulation do you consider hinder or enhance your learning? Why? (In specific physical environment, content of the cases, organization of the simulation, etc.)

- What are the essential conditions for you to learn in simulation?

- What are the impacts of simulation on learning from your perspective? 